\title{
The STAR Data Reporting Guidelines for Clinical High Altitude Research
}

\author{
Monika Brodmann Maeder, ${ }^{1,2}$ Hermann Brugger, ${ }^{1}$ Matiram Pun, ${ }^{1}$ \\ Giacomo Strapazzon, ${ }^{1}$ Tomas Dal Cappello, ${ }^{1}$ Marco Maggiorini, ${ }^{3}$ \\ Peter Hackett, ${ }^{4}$ Peter Bärtsch, ${ }^{5}$ Erik R. Swenson, ${ }^{6,7}$ Ken Zafren ${ }^{8}$ (STAR Core Group), \\ and the STAR Delphi Expert Group*
}

\begin{abstract}
Brodmann Maeder, Monika, Hermann Brugger, Matiram Pun, Giacomo Strapazzon, Tomas Dal Cappello, Marco Maggiorini, Peter Hackett, Peter Bärtsch, Erik R. Swenson, Ken Zafren (STAR Core Group), and the STAR Delphi Expert Group. The STAR data reporting guidelines for clinical high altitude research. High Alt Med Biol. 19:7-14, 2018. Aims: The goal of the STAR (STrengthening Altitude Research) initiative was to produce a uniform set of key elements for research and reporting in clinical high-altitude (HA) medicine. The STAR initiative was inspired by research on treatment of cardiac arrest, in which the establishment of the Utstein Style, a uniform data reporting protocol, substantially contributed to improving data reporting and subsequently the quality of scientific evidence. Materials and Methods: The STAR core group used the Delphi method, in which a group of experts reaches a consensus over multiple rounds using a formal method. We selected experts in the field of clinical HA medicine based on their scientific credentials and identified an initial set of parameters for evaluation by the experts.

Results: Of 51 experts in HA research who were identified initially, 21 experts completed both rounds. The experts identified 42 key parameters in 5 categories (setting, individual factors, acute mountain sickness and HA cerebral edema, HA pulmonary edema, and treatment) that were considered essential for research and reporting in clinical HA research. An additional 47 supplemental parameters were identified that should be reported depending on the nature of the research.
\end{abstract}

Conclusions: The STAR initiative, using the Delphi method, identified a set of key parameters essential for research and reporting in clinical HA medicine.

Keywords: clinical research; Delphi method; guidelines; high altitude; Utstein style

\section{Introduction}

$\mathbf{H}$ IGH-ALTITUDE (HA) RESEARCH is of international interest for clinicians and translational scientists. HA research has broad clinical implications due to the nature of hypobaric hypoxic exposure and its physiological conse- quences. Since the inception of HA field research by teams of clinicians, such as the Silver Hut Expedition in 1960-1961 (Michel and Milledge, 1963; Milledge, 1963, 2010), there has been a steady increase in the number of clinical and basic science research studies related to HA medicine (Brugger et al., 2017). Despite previous efforts to standardize clinical

\footnotetext{
${ }^{1}$ Institute of Mountain Emergency Medicine, EURAC Research, Bolzano, Italy.

${ }^{2}$ Department of Emergency Medicine, Inselspital, Bern University Hospital and University of Bern, Bern, Switzerland.

${ }^{3}$ Institute of Emergency Care Medicine, University Hospital, Zurich, Switzerland.

${ }^{4}$ Department of Medicine, Altitude Research Center, Division of Pulmonary and Critical Care Medicine, University of Colorado, Aurora, Colorado.

${ }^{5}$ Department of Internal Medicine, University Hospital, Heidelberg, Germany.

${ }^{6}$ VA Puget Sound Health Care System, Pulmonary and Critical Care Medicine, University of Washington, Seattle, Washington.

${ }^{7}$ Division of Pulmonary and Critical Care Medicine, University of Washington, Seattle, Washington.

${ }^{8}$ Department of Emergency Medicine, Stanford University Medical Center, Stanford, California.

*See Acknowledgments section.
}

(C) Monika Brodmann Maeder et al., 2018; Published by Mary Ann Liebert, Inc. This Open Access article is distributed under the terms of the Creative Commons Attribution Noncommercial License (http://creativecommons.org/licenses/by-nc/4.0/) which permits any noncommercial use, distribution, and reproduction in any medium, provided the original author(s) and the source are cited. 
parameters of HA-related illnesses, such as the Lake Louise consensus acute mountain sickness (AMS) score (Roach et al., 1991), there remains a lack of uniformity in defining and reporting basic parameters in clinical HA research. Due to the lack of uniformity, studies are heterogeneous. Many studies incompletely report key data. This makes it difficult to reproduce or compare studies and to perform reliable metaanalyses. To strengthen clinical HA research, it is necessary to formulate a common language and standard definitions.

The STAR initiative was inspired by research on treatment of cardiac arrest, in which the establishment of the Utstein Style, a uniform data reporting protocol, substantially contributed to improving data reporting and subsequently the quality of scientific evidence (Cummins et al., 1991). The Utstein Style was developed in 1991 by a group of experts. It was the first consensus-based guideline for uniform data reporting. The expert group defined a set of data elements essential for research in resuscitation from out-of-hospital cardiac arrest. The recommendations have been updated periodically to reflect current evidence. They have enabled researchers to compare studies effectively using meta-analyses. Subsequently, standardized data reporting was adopted in a number of related areas, such as in-hospital resuscitation (Cummins et al., 1997), pediatric resuscitation (Zaritsky et al., 1995), and laboratory CPR research (Idris et al., 1996). Checklists have been introduced in other fields of research, including PRISMA for sys- tematic reviews and meta-analyses (Liberati et al., 2009; Moher et al., 2009), STROBE for observational studies in epidemiology (von Elm et al., 2014), CONSORT for randomized controlled trials (Altman, 1996; Moher et al., 2010), SPIRIT for standard protocol items for clinical trials (Chan et al., 2013), and CARE for case reports (Rison et al., 2013). The goal of these guidelines has been to render data reporting and research more consistent and comparable.

A group of experts in the field of clinical HA research, the STAR Core Group, established the "Strengthening Altitude Research" (STAR) project. As in the process used to develop the Utstein Style, the STAR project involved a large group of experts in clinical HA research, who produced consensusbased guidelines for standardized data reporting. Because the community of researchers in HA is small, spread all over the world and rarely meets at conferences, face-to-face meetings were not practical. The STAR Core Group therefore made use of an internet-based Delphi process facilitated by a research group at the EURAC Research Institute of Mountain Emergency Medicine in Bolzano, Italy.

\section{Materials and Methods}

\section{Delphi method}

The Delphi method is a structured, deliberative process that uses a series of rounds with a group of experts who

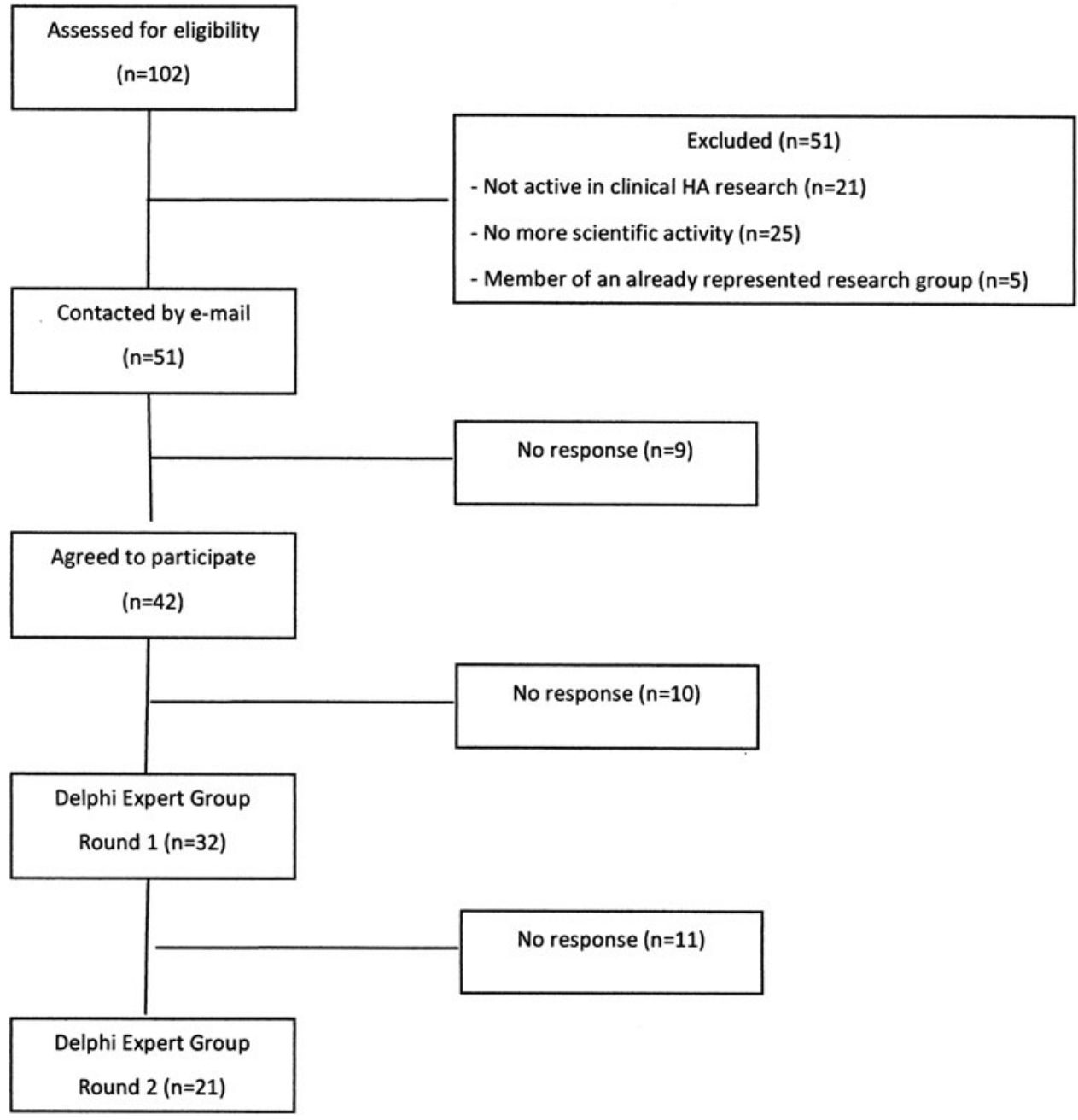

FIG. 1. STAR Delphi Expert selection and evolution. 
collaborate anonymously. It was developed and described by Brown, Dalkey, and Helmer from the RAND Corporation in the 1960s (Dalkey, 1963; Brown, 1968) with the goal of obtaining the most reliable consensus of opinion within a group of experts. The Delphi method is a widely used technique to find consensus from respondents within their domain of expertise (Hsu Chia-Chien, 2007). In this process, experts are repeatedly consulted either by interview or questionnaire to avoid direct confrontation between the experts. This is to ensure that the assessment of parameters is purely based on independent rational judgment. An administrative group is responsible for preparing the questionnaires or conducting interviews, summarizing the results anonymously, feeding the results back to the experts, and starting another round until consensus is achieved at a predefined threshold. The STAR core group used an electronic implementation of the Delphi method. The experts anonymously rated the predefined parameters as being either core or supplemental. The experts could also provide comments and suggest additional parameters. An $80 \%$ consensus was the threshold for a parameter to be accepted as core parameter. All the other parameters were included in the list of either supplemental or unnecessary ("futile") parameters.

\section{Selection of experts}

Experts in HA medicine were identified as candidates for the STAR Delphi process using citations from the reference book "High Altitude Medicine and Physiology" (West et al., 2012) and by a PubMed search for authors with at least five original articles in the field of HA medicine between January 2000 and January 2016. The list of 101 potential experts was reviewed by the Core Group. Researchers who were members of a research group that was already represented in the list of candidates for the Delphi group by at least one expert, candidates who were not active in clinical research on acute HA illnesses, and candidates who were no longer active in the field were excluded. In all, 51 experts were identified as candidates and invited by email to participate in the STAR Delphi process (Fig. 1).

\section{Selection of STAR parameters}

Clinically relevant parameters from the HA medicine literature were first identified by the STAR Core Group. The parameters were then grouped by categories and entered into an Excel spreadsheet. For STAR Delphi Round 1, 162 parameters were identified and divided into 7 categories: setting/ context, individual factors, AMS, high-altitude cerebral edema (HACE), high-altitude pulmonary edema (HAPE), treatment, and definitions. The parameters were then graded by the STAR Delphi experts as follows: "core," "supplemental," or "futile." For inclusion as a core parameter, at least $80 \%$ of the experts had to rate a parameter as "core." The definition of a parameter as "core" meant that it should be reported in every clinical HA research article. "Supplemental" meant that a parameter may be reported depending on the research question. "Futile" parameters were defined as being either outdated or unnecessary. "Futile" parameters were eliminated in Round 1. In Round 2, all remaining parameters were classified as either "core" or "supplemental."

\section{Results}

Before Round 1, 51 experts were selected and invited to participate in the STAR Delphi process. Of the 51 invited
Table 1. STAR Core Parameters

\begin{tabular}{|c|c|}
\hline Section & Parameters \\
\hline $\begin{array}{l}\text { Section 1: } \\
\text { Setting } \\
(n=6)\end{array}$ & $\begin{array}{l}\text { [1.1] Study location } \\
\text { [1.2] Setting } \\
\text { [1.3] Altitude } \\
\text { [1.4] Starting point of the ascent } \\
\text { [1.5] Maximum altitude reached } \\
\text { [1.6] Mode of ascent (active or passive) }\end{array}$ \\
\hline $\begin{array}{l}\text { Section 2: } \\
\text { Individual } \\
\text { factors } \\
(n=10)\end{array}$ & $\begin{array}{l}\text { [2.1] Age } \\
\text { [2.2] Sex } \\
\text { [2.3] Preexisting altitude exposure } \\
\text { [2.4] High-altitude native } \\
\text { [2.5] Preexisting health conditions } \\
\text { [2.6] History of prior AMS } \\
\text { [2.7] History of prior HACE } \\
\text { [2.8] History of prior HAPE } \\
\text { [2.9] Preacclimatization } \\
\text { [2.10] Altitude of residence }\end{array}$ \\
\hline $\begin{array}{l}\text { Section 3: AMS } \\
\text { and HACE } \\
(n=11)\end{array}$ & $\begin{array}{l}\text { [3.1] Headache } \\
\text { [3.2] Gastrointestinal symptoms } \\
\text { [3.3] Fatigue/weakness } \\
\text { [3.4] Dizziness/lightheadedness } \\
\text { [3.5] Ataxia } \\
\text { [3.6] Change in mental status } \\
\text { [3.7] AVPU } \\
\text { [3.8] SpO } \\
\text { [3.9] Time of fulfilling AMS definition- } \\
\text { this suggests time of onset, not } \\
\text { diagnosis } \\
\text { [3.10] Time of fulfilling HACE } \\
\text { definition-same, needs to be } \\
\text { consistent with text } \\
\text { [3.11] Lake Louise AMS Score } 2017\end{array}$ \\
\hline $\begin{array}{l}\text { Section 4: } \\
\text { HAPE } \\
(n=11)\end{array}$ & $\begin{array}{l}\text { [4.1] Weakness/decreased exercise } \\
\text { performance } \\
\text { [4.2] Dyspnea at rest } \\
\text { [4.3] Cough } \\
\text { [4.4] Tachypnea } \\
\text { [4.5] Orthopnea } \\
\text { [4.6] Pink frothy sputum } \\
\text { [4.7] Respiratory rate } \\
\text { [4.8] Heart rate } \\
\text { [4.9] } \mathrm{SpO}_{2} \\
\text { [4.10] Rales and wheezing } \\
\text { [4.11] Time of fulfilling HAPE } \\
\text { definition-as above }\end{array}$ \\
\hline $\begin{array}{l}\text { Section 5: } \\
\text { Therapy } \\
(n=4)\end{array}$ & $\begin{array}{l}\text { [5.1] List all drugs with generic names, } \\
\text { dosages, mode of administration, } \\
\text { dosage intervals, and indication } \\
\text { [5.2] Supplemental oxygen } \\
\text { [5.3] Hyperbaric bag } \\
\text { [5.4] Descent }\end{array}$ \\
\hline
\end{tabular}

AMS, acute mountain sickness; AVPU, responsiveness assessment, see text; HACE, high-altitude cerebral edema; HAPE, highaltitude pulmonary edema; $\mathrm{SpO}_{2}$, oxygen saturation as measured by pulse oximetry.

experts, 42 experts agreed and 32 completed Round 1. For Round 2, 21 experts returned ratings.

In Round 1, 32 of the 162 proposed parameters reached consensus as core parameters. The Delphi experts not only rated the predetermined parameters but also provided a large number of comments on the existing parameters, mainly related to the section of drugs. Moreover, they suggested additional parameters for consideration. The feedback of the 
experts resulted in major changes for Round 2: the AMS and HACE sections were combined. In the Therapy section, the STAR Core Group decided to replace the list of drugs with the sentence to list all drugs used (see Section 5: Therapy). Newly proposed parameters were added to the list, and the list of futile parameters was withdrawn. Therefore, in Round 2, the Delphi experts rated the parameters remaining from Round 1 and the additional parameters as "core" or "supplemental." In Round 2, eight more parameters reached the threshold of $\geq 80 \%$ consensus and were added to the list of core parameters. Two parameters received ratings between $70 \%$ and $80 \%$ and were added as core parameters under the discretion of the STAR core group. Altogether, 42 core parameters (Table 1) and 47 supplemental parameters (Table 2) were identified.

\section{STAR Core Parameters (Table 1)}

\section{Section 1: Setting}

[1.1] Study location. The geographic location of the research such as Kilimanjaro, Tanzania, Khumbu of Nepal, Capanna Margherita of Italy, or Barcroft Station at White Mountain Research Center, California.

[1.2] Setting. The setting refers to the study environment, such as trekking, expedition, or chamber (normobaric or hypobaric). Setting applies to case reports as well as to formal studies.

[1.3] Altitude or simulated altitude. Altitude range at which the study was conducted (study starting or enrollment point to the study end point) or the altitude of a care setting or research facility. The altitudes of data collection or of the occurrence and management of clinical cases should be reported.

[1.4] Starting point of ascent or simulated altitude. The altitude at which individuals started trekking, hiking, or climbing (for both active and passive ascents).

[1.5] Maximum altitude reached. The altitude achieved at a particular time or day, including a day-hike if the sleeping altitude was lower than day-hike. Alternatively, provision of a full ascent profile should be reported. In the profile, start and end of the ascent, altitude reached every day, and sleeping altitude should be reported.

[1.6] Mode of ascent (active or passive). The means of gaining altitude either actively, for example, by walking or trekking, or passively, such as by chamber, car, helicopter, airplane, or riding animal, including horse, mule, or yak.

\section{Section 2: Individual characteristics}

[2.1] Age. The age (in years) of the individual at the start of the study.

[2.2] Sex. Male or female.

[2.3] Preexisting altitude exposure. Previous exposure to a defined altitude by an individual within a previously defined time period. Altitude and duration of stay should be reported.

[2.4] HA native. A person who was born and raised at HA (typically $>2500-3000 \mathrm{~m}$ ), usually with previous generations also resident at $\mathrm{HA}$.
Table 2. StaR Supplemental Parameters

\begin{tabular}{|c|c|}
\hline Setting & $\begin{array}{l}\text { Latitude } \\
\text { GPS location } \\
\text { Ambient temperature during } \\
\text { measurement } \\
\text { Wind } \\
\text { Precipitation } \\
\text { Study date } \\
\text { Measured barometric pressure } \\
\text { Altitude at which one sleeps each night } \\
\text { Air pollution }\end{array}$ \\
\hline Individual factors & $\begin{array}{l}\text { Occupation } \\
\text { Ethnicity } \\
\text { Nutrition (special diet, nutritional } \\
\quad \text { supplements, caffeine, etc) } \\
\text { Fluid balance/hydration } \\
\text { Objective fitness measurement } \\
\text { Training (please define) } \\
\text { Regular smoker } \\
\text { Regular alcohol consumer } \\
\text { Minimal physical assessment (respiratory } \\
\text { rate, heart rate, blood pressure, and } \\
\text { blood oxygen saturation at rest) } \\
\text { Hypoxic ventilatory response } \\
\text { Illness during study period }\end{array}$ \\
\hline Symptoms & $\begin{array}{l}\text { Difficulty sleeping } \\
\text { Drowsiness }\end{array}$ \\
\hline Signs & $\begin{array}{l}\text { Peripheral edema } \\
\text { Central cyanosis } \\
\text { Chest tightness or congestion } \\
\text { Blood pressure } \\
\text { Body temperature }\end{array}$ \\
\hline Scores & $\begin{array}{l}\text { Time of first recorded AMS symptom } \\
\text { Time of first recorded HACE symptom } \\
\text { Time of first recorded HAPE symptom } \\
\text { AMS-C of ESQ-III }\end{array}$ \\
\hline Additional exams & $\begin{array}{l}\mathrm{CRP} \text { and white cell count } \\
\text { End-tidal } \mathrm{CO}_{2} \\
\text { NIRS } \\
\text { Spirometry/oscillatory resistance } \\
\text { Hypoxic ventilatory response } \\
\text { Respiratory muscle strength } \\
\text { Neuropsychometrics }\end{array}$ \\
\hline Imaging & $\begin{array}{l}\text { Pulmonary ultrasound } \\
\text { Echocardiography } \\
\text { Optic nerve sheath ultrasound } \\
\text { TCD } \\
\text { Chest X-ray } \\
\text { Cerebral CT scan } \\
\text { Thoracic CT scan } \\
\text { Cerebral MRI }\end{array}$ \\
\hline Therapy & CPAP \\
\hline
\end{tabular}

AMS-C, AMS-cerebral; $\mathrm{CO}_{2}$, carbon dioxide; CPAP, Continuous Positive Airway Pressure; CRP, C-reactive protein; CT scan, Computed Tomography Scan; ESQ-III, Environmental Symptom QuestionnaireIII; GPS, global positioning system; MRI, Magnetic Resonance Imaging; NIRS, Near-Infrared Spectroscopy; TCD; Transcranial Doppler.

[2.5] Preexisting health conditions. Preexisting health conditions should be reported. Examples of preexisting conditions are as follows: cardiovascular such as hypertension or previous myocardial infarction, pulmonary such as asthma or chronic obstructive pulmonary disease, neurological such as migraine or previous stroke, or other conditions such as diabetes, sleep breathing disorders, inherited genetic disorders, or previous solid organ transplantation. 
Table 3. Lake Louise Acute Mountain SICKNESS SCORE 2017

Headache:

0 None at all

$1 \mathrm{~A}$ mild headache

2 Moderate headache

3 Severe headache, incapacitating

Gastrointestinal symptoms:

0 Good appetite

1 Poor appetite or nausea

2 Moderate nausea or vomiting

3 Severe nausea and vomiting, incapacitating

Fatigue and/or weakness:

0 Not tired or weak

1 Mild fatigue/weakness

2 Moderate fatigue/weakness

3 Severe fatigue/weakness, incapacitating

Dizziness/lightheadedness:

0 No dizziness/lightheadedness

1 Mild dizziness/lightheadedness

2 Moderate dizziness/lightheadedness

3 Severe dizziness/lightheadedness, incapacitating

Lake Louise AMS functional score

Overall, if you had AMS symptoms, how did they affect your activities?

0 Not at all

1 Symptoms present, but did not force any change in activity or itinerary

2 My symptoms forced me to stop the ascent or to go down on my own power

3 Had to be evacuated to a lower altitude

Roach et al. (2017).

[2.6] History of prior AMS. History of AMS during previous HA exposure. If available, report the altitude(s) at which AMS was diagnosed and reported signs and symptoms.

[2.7] History of prior HACE. History of HACE during previous HA exposure(s). If available, report the altitude(s) at which HACE was diagnosed and reported signs and symptoms.

[2.8] History of prior HAPE. History of HAPE during previous HA exposure(s). If available, report the altitude(s) at which HAPE was diagnosed and reported signs and symptoms.

[2.9] Preacclimatization. The number of days spent above $3000 \mathrm{~m}$ in the previous 2 months, excluding the current ascent.

[2.10] Altitude of residence. The altitude at which the subject lives.

\section{Section 3: AMS and HACE}

[3.1] Headache. Headache with a recent gain of altitude is considered an HA headache, unless otherwise specified. If not an HA headache, the type (e.g., cluster, tension headache, or migraine) should be specified.

[3.2] Gastrointestinal symptoms. Gastrointestinal symptoms should be reported according to the new Lake Louise AMS Score 2017 (Table 3) (Roach et al., 2017).
Table 4. Lake Louise Consensus Definitions of High-Altitude Cerebral Edema and High-Altitude Pulmonary Edema

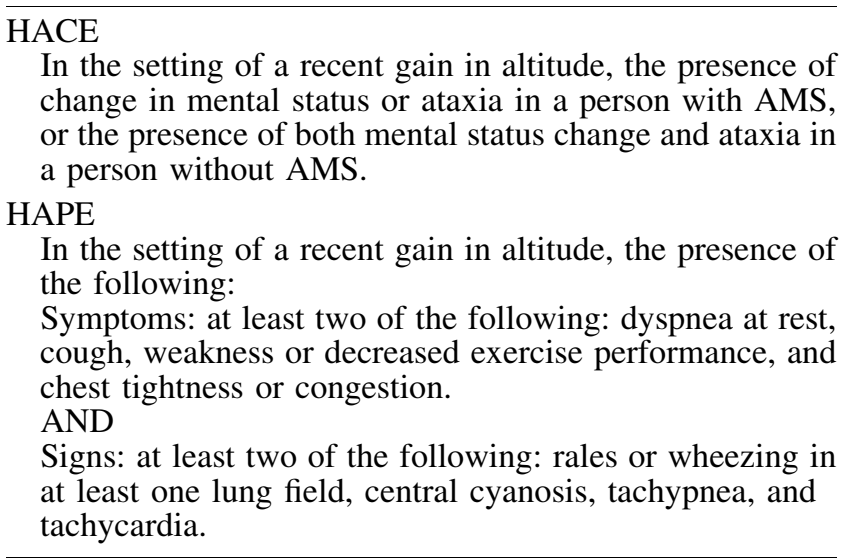

Adapted from Lake Louise Consensus Definitions of AltitudeRelated Health Problems (Roach et al., 1991).

[3.3] Fatigue/weakness. Symptoms of fatigue or weakness during ascent should be reported according to the new Lake Louise AMS Score 2017 (Table 3).

[3.4] Dizziness/lightheadedness. Symptoms of dizziness or lightheadedness should be reported according to the new Lake Louise AMS Score 2017 (Table 3).

[3.5] Ataxia (HACE). Unsteady gait or inability to walk in straight line heel-to-toe (tandem gait).

[3.6] Change in mental status (HACE). Assessment of cognitive and behavioral functioning of the individual (orientation to person, place and date; somnolence/confusion/ coma).

[3.7] AVPU (HACE). Responsiveness assessment, based on the descriptions as " $A$ " for alert, " $V$ " for responsive to verbal stimulation, " $\mathrm{P}$ " for responsive to painful (or other noxious) stimuli, and " $U$ " for unresponsiveness.

[3.8] $\mathrm{SpO}_{2} \%$. The blood oxygen saturation in percentage measured by pulse oximeter in the periphery, for example, finger or ear lobe.

[3.9] Time of AMS onset. The length of time from arrival to onset of AMS after arriving at the HA location at which AMS was diagnosed. The diagnosis of AMS should be established by the New Lake Louise AMS Score (Table 3). The duration from arrival to onset should be reported in hours or days.

[3.10] Time of HACE onset. The length of time from arrival to onset of HACE after arriving at the HA location at which HACE was diagnosed. The diagnosis of HACE should be established by the current Lake Louise Consensus criteria (Table 4). The duration from arrival to onset should be reported in hours or days.

[3.11] Lake Louise AMS Score 2017. For the new Lake Louise AMS Score 2017 for the diagnosis of AMS (Table 3). 
The score is intended for use by investigators studying AMS and is defined as sum of the four symptoms. AMS definition is positive with a headache score of at least one point and a total score of at least three points (Roach et al., 2017).

\section{Section 4: HAPE}

[4.1] Weakness or decreased exercise performance. Feeling weak or having the perception of decreased exercise performance.

[4.2] Dyspnea at rest. Shortness of breath at rest.

[4.3] Cough. Cough can be productive or dry (nonproductive).

[4.4] Tachypnea. Abnormally rapid breathing. A faster than normal rate of breathing at rest. The threshold for tachypnea varies depending on sex, fitness, preexisting conditions, and altitude.

[4.5] Orthopnea. Shortness of breath when lying down.

[4.6] Pink frothy sputum. Sputum produced during cough that is aerated (frothy) and pink colored (suggestive of blood).

[4.7] Respiratory rate. Number of breaths per minute counted by an observer or measured by an equipment.

[4.8] Heart rate. Number of beats per minute recorded by an observer or by a device.

[4.9] $\mathrm{SpO}_{2} \%$. Hemoglobin oxygen saturation measured peripherally (usually finger or ear lobe) by pulse oximeter. $\mathrm{SpO}_{2}$ is reported as the percentage of hemoglobin that is bound to oxygen. Oxygen saturation by arterial blood gas $\left(\mathrm{SaO}_{2}\right)$ may be reported, but is not necessary in most cases.

[4.10] Crackles (rales) or wheezing in at least one lung field. Pathological breath sounds during chest auscultation, described as crackles (rales), which are coarse crackling sounds, or wheezes, which are high-pitched whistling sounds.

[4.11] Time of HAPE onset. The length of time from arrival to onset of HAPE after arriving at the HA location at which HAPE was diagnosed. The diagnosis of HAPE should be established by the Lake Louise Consensus criteria (Table 4). The duration from arrival to onset should be reported in hours or days.

\section{Section 5: Therapy}

[5.1] List of all drugs used. Drugs or medication of any type used during HA sojourn for the prevention or treatment of altitude-related health problems or for preexisting conditions, delivered orally or parenterally. For each drug, report the generic name, dosage, mode of administration, dosage intervals, and indication.

[5.2] Supplemental oxygen. The flow of supplemental oxygen in $\mathrm{L} / \mathrm{min}$, from bottled oxygen or from a concentrator, provided to a patient through mask or cannula. For intubated patients, report the fraction of inspired oxygen $\left(\mathrm{F}_{\mathrm{i}} \mathrm{O}_{2}\right)$.
[5.3] Portable hyperbaric chamber (simulated descent). An air-impermeable bag that completely envelops a patient and is inflated to a significant pressure above ambient atmospheric pressure. Specific models include the following: Gamow ${ }^{\circledR}$ bag, Certec ${ }^{\circledR}$ bag, and PAC ${ }^{\circledR}$ (Portable Altitude Chamber). Indicate duration(s) in the chamber and pressure of inflation or equivalent altitude maintained during treatment.

[5.4] Descent (actual descent). Lowering the altitude by physically moving the individuals by any means, such as walking or climbing, riding on an animal, by vehicle, or air, or by being carried by porter from higher to lower altitude. This should be quantified by the difference in altitude and the amount of time spent descending.

\section{Discussion}

A core group of experts in HA research convened an international group of 42 colleagues with appropriate scientific credentials to participate in a Delphi process to develop consensus guidelines for data reporting in clinical HA medicine research. From a preliminary list of 98 parameters that had been defined by the STAR core group, the experts reached $\geq 80 \%$ consensus on each of 42 core parameters for clinical research in HA medicine. These parameters should be mandatory for research proposals and reports of HA. They also reached consensus on a second open-ended list of 47 supplemental parameters (Table 2). The supplementary parameters depend on the specific research question. Reporting of supplemental parameters is not mandatory for every research article.

Reproducibility of study results is one of the most concerning issues in natural and medical sciences. Since the 1990s, guidelines have been developed for reporting results in many fields of medical research in an attempt to improve reproducibility of research. Guidelines include the Utstein Style (Cummins et al., 1991, 1997; Zaritsky et al., 1995; Idris et al., 1996), PRISMA (Liberati et al., 2009; Moher, et al., 2009), STROBE (von Elm et al., 2014), CONSORT (Altman, 1996; Moher et al., 2010), SPIRIT (Chan et al., 2013), and CARE (Rison et al., 2013). Developing guidelines for data reporting in clinical HA medicine is important because the number of studies is rapidly increasing. There are many advantages to better uniformity of clinical HA research studies. Sample sizes are often small in prospective HA studies. Studies are heterogeneous, especially in relation to study setting, study populations, and definitions of altitude illnesses. Research at the Capanna Regina Margherita, one of the most frequently used HA field sites in the Alps, is based on an ascent from 490 to $4559 \mathrm{~m}$ in around 24-36 hours (Hochstrasser et al., 1986; Ferrazzini et al., 1987; Goerre et al., 1995; Scherrer et al., 1996; Agostoni et al., 2013). The "classic" ascent from Lukla $(2850 \mathrm{~m})$ to Everest Base Camp (5380 $\mathrm{m})$ takes $7-10$ days. These settings substantially differ in altitude and ascent rate. Confounding factors such as the means of ascent, varying by speed of ascent and level of exercise, and environmental factors, such as exposure to temperature extremes, wind, humidity, and precipitation, are poorly reported. Similar considerations apply to different study populations, such as subjects from different ethnicities, lowlanders versus highlanders, and subjects with different degrees of acclimatization. 
Use of the 42 core and 47 supplemental parameters can facilitate comparisons among studies and can provide a basis to perform reliable meta-analyses, strengthening the findings and providing robust evidence for prevention, diagnosis, and treatment of altitude illnesses. This open-ended list can shed light on new developments in clinical HA research and needs regular updates. We hope that use of the STAR guidelines will improve data reporting in HA research, improve reproducibility, and facilitate comparison among studies.

\section{Limitations}

In addition to the 51 international experts identified by the STAR group, there may have been many other equally qualified experts. We do not know how the results would have differed if additional experts had been identified. We also do not know how results would have differed if the 19 identified experts who did not collaborate had participated in one or more rounds or if the 11 experts who dropped out after Round 1 had participated in both rounds. We do not have any information about reasons for nonparticipation at any of the stages.

STAR Delphi Round 1 revealed potential flaws in the list of parameters. There was considerable discussion regarding the definitions of AMS, HACE, and HAPE. Some experts questioned the clinical significance and consistency of some of the diagnostic criteria of AMS, particularly the category of sleep disturbance. At the time of the Delphi process, the STAR core group based the STAR criteria on the 1991 Lake Louise Consensus definitions of HA illnesses. Coincidentally, the Lake Louise AMS Score was under revision when the STAR article was submitted. For the revised STAR article, the STAR Core Group integrated the new Lake Louise AMS Score 2017 (Roach et al., 2017) (Table 3).

\section{Conclusions}

The STAR consensus guidelines, developed by a Delphi process, describe 42 core parameters that should be reported in clinical research articles on HA-related health problems and 47 supplemental parameters that should be reported, depending on the research question. We anticipate regular updates of the guidelines as new evidence is published in the dynamic field of clinical HA research.

\section{Acknowledgments}

We would like to express our sincere thanks to Miriam Gottardi for administrative support during the STAR Delphi rounds and to Martin Palma for technical assistance in processing the data. We would also like to thank Sandro Malacrida, $\mathrm{PhD}$, and Emily Procter, MSc, who assisted with data collection in the initial phase of STAR Delphi process. Finally, we would like to thank all 32 Delphi experts who participated in the process, with special thanks to the 21 experts who completed both rounds. STAR Delphi Expert Group: J.K. Baillie (United Kingdom); B. Basnyat (Nepal); C.M. Beall (USA); B.A. Beidleman (USA); M.M. Berger (Austria); K.R. Burgess (Australia); M. Burtscher (Austria); A. Cogo (Italy); C. Dehnert (Switzerland); J.H. Gertsch (USA); M.P. Grocott (United Kingdom); N.S. Harris (USA); U. Hefti (Switzerland); C.H. Imray (United Kingdom); B. Kayser (Switzerland); M.S. Koehle (Canada); S. Kriemler (Switzerland); J.A. Loeppky (USA); A.M. Luks (USA); C.
Lundby (Switzerland); M.J. MacInnis (Canada); T. Merz (Switzerland); S.R. Muza (USA); L. Pratali (Italy); J.P. Richalet (France); S. Rimoldi (Switzerland); R.C. Roach (USA); P. Robach (France); U. Scherrer (Switzerland); A.W. Subudhi (USA); M.H. Wilson (United Kingdom); and D.R. Woods (United Kingdom).

\section{Author Disclosure Statement}

No competing financial interests exist.

\section{References}

Agostoni P, Swenson ER, Fumagalli R, Salvioni E, Cattadori G, Farina S, Bussotti M, Tamplenizza M, Lombardi C, Bonacina D, Brioschi M, Caravita S, Modesti P, Revera M, Giuliano A, Meriggi P, Faini A, Bilo G, Banfi C, and Parati G. (2013). Acute high-altitude exposure reduces lung diffusion: Data from the HIGHCARE Alps project. Respir Physiol Neurobiol 188:223-228.

Altman DG. (1996). Better reporting of randomised controlled trials: The CONSORT statement. BMJ 313:570-571.

Brown BB. (1968). DELPHI PROCESS: A Methodology Used for the Elicitation of Opinions of Experts. R. Corporation, Santa Monica, CA. ASTME Vectors: 14.

Brugger H, Pun M, Swenson ER, and Falk M. (2017). Research in high-altitude and mounain emergency medicine: Is methodology key? High Alt Med Biol [Epub ahead of print]; DOI: 10.1089/ham.2017.0124.

Chan AW, Tetzlaff JM, Altman DG, Laupacis A, Gotzsche PC, Krleza-Jeric K, Hrobjartsson A, Mann H, Dickersin K, Berlin JA, Dore CJ, Parulekar WR, Summerskill WS, Groves T, Schulz KF, Sox HC, Rockhold FW, Rennie D, and Moher D. (2013). SPIRIT 2013 statement: Defining standard protocol items for clinical trials. Ann Intern Med 158:200-207.

Cummins RO, Chamberlain D, Hazinski MF, Nadkarni V, Kloeck W, Kramer E, Becker L, Robertson C, Koster R, Zaritsky A, Bossaert L, Ornato JP, Callanan V, Allen M, Steen P, Connolly B, Sanders A, Idris A, and Cobbe S. (1997). Recommended guidelines for reviewing, reporting, and conducting research on in-hospital resuscitation: The in-hospital "Utstein style". A statement for healthcare professionals from the American Heart Association, the European Resuscitation Council, the Heart and Stroke Foundation of Canada, the Australian Resuscitation Council, and the Resuscitation Councils of Southern Africa. Resuscitation 34:151-183.

Cummins RO, Chamberlain DA, Abramson NS, Allen M, Baskett PJ, Becker L, Bossaert L, Delooz HH, Dick WF, Eisenberg MS, et al. (1991). Recommended guidelines for uniform reporting of data from out-of-hospital cardiac arrest: The Utstein Style. A statement for health professionals from a task force of the American Heart Association, the European Resuscitation Council, the Heart and Stroke Foundation of Canada, and the Australian Resuscitation Council. Circulation 84:960-975.

Dalkey NHO. (1963). An experimental application of the Delphi method to the use of experts. Manag Sci 9:458-467.

Ferrazzini G, Maggiorini M, Kriemler S, Bartsch P, and Oelz O. (1987). Successful treatment of acute mountain sickness with dexamethasone. Br Med J (Clin Res Ed) 294:1380-1382.

Goerre S, Wenk M, Bartsch P, Luscher TF, Niroomand F, Hohenhaus E, Oelz O, and Reinhart WH. (1995). Endothelin1 in pulmonary hypertension associated with high-altitude exposure. Circulation 91:359-364.

Hochstrasser J, Nanzer A, and Oelz O. (1986). Altitude edema in the Swiss Alps. Observations on the incidence and clinical 
course in 50 patients 1980-1984 [in German]. Schweiz Med Wochenschr 116:866-873.

Hsu C-C, and Sandford BA. (2007). The Delphi Technique: Making Sense of Consensus. Practical Assessment Research \& Evaluation 12(10).

Idris AH, Becker LB, Ornato JP, Hedges JR, Bircher NG, Chandra NC, Cummins RO, Dick W, Ebmeyer U, Halperin HR, Hazinski MF, Kerber RE, Kern KB, Safar P, Steen PA, Swindle MM, Tsitlik JE, von Planta I, von Planta M, Wears RL, and Weil MH. (1996). Utstein-style guidelines for uniform reporting of laboratory CPR research. A statement for healthcare professionals from a Task Force of the American Heart Association, the American College of Emergency Physicians, the American College of Cardiology, the European Resuscitation Council, the Heart and Stroke Foundation of Canada, the Institute of Critical Care Medicine, the Safar Center for Resuscitation Research, and the Society for Academic Emergency Medicine. Resuscitation 33:69-84.

Liberati A, Altman DG, Tetzlaff J, Mulrow C, Gotzsche PC, Ioannidis JP, Clarke M, Devereaux PJ, Kleijnen J, and Moher D. (2009). The PRISMA statement for reporting systematic reviews and meta-analyses of studies that evaluate healthcare interventions: Explanation and elaboration. BMJ 339:b2700.

Michel CC, and Milledge JS. (1963). Respiratory regulation in man during acclimatization to high altitude. J Physiol 168:631-643.

Milledge JS. (1963). Electrocardiographic changes at high altitude. Br Heart J 25:291-298.

Milledge JS. (2010). The Silver Hut expedition, 1960-1961. High Alt Med Biol 11: 93-101.

Moher D, Hopewell S, Schulz KF, Montori V, Gotzsche PC, Devereaux PJ, Elbourne D, Egger $M$, and Altman DG. (2010). CONSORT 2010 explanation and elaboration: Updated guidelines for reporting parallel group randomised trials. BMJ 340:c869.

Moher D, Liberati A, Tetzlaff J, Altman DG, and Group P. (2009). Preferred reporting items for systematic reviews and meta-analyses: The PRISMA statement. Ann Intern Med 151: 264-269, W264.

Rison RA, Kidd MR, and Koch CA. (2013). The CARE (CAse REport) guidelines and the standardization of case reports. J Med Case Rep 7:261.
Roach RC, Hackett PH, Oelz O, Bärtsch P, Luks AM, MacInnis MJ, Baillie JK, and The Lake Louise AMS Score Consensus Committee. (2018). The 2018 Lake Louise Acute Mountain Sickness Score. High Alt Med Biol 19:4-6.

Roach RC, Bärtsch P, Oelz O, and Hackett PH. (1991). The Lake Louise Acute Mountain Sickness Scoring System. Lake Louise AMS Scoring System Consensus Conference. Hypoxia and Molecular Medicine. Lake Louise/Canada.

Scherrer U, Vollenweider L, Delabays A, Savcic M, Eichenberger U, Kleger GR, Fikrle A, Ballmer PE, Nicod P, and Bartsch P. (1996). Inhaled nitric oxide for high-altitude pulmonary edema. N Engl J Med 334:624-629.

von Elm E, Altman DG, Egger M, Pocock SJ, Gotzsche PC, Vandenbroucke JP, and Initiative S. (2014). The Strengthening the Reporting of Observational Studies in Epidemiology (STROBE) Statement: Guidelines for reporting observational studies. Int J Surg 12:1495-1499.

West JB, Schoene RB, Luks AM, and Milledge JS. (2012). High Altitude Medicine and Physiology. Am J Respir Crit Care Med 186:1229-1237.

Zaritsky A, Nadkarni V, Hazinski MF, Foltin G, Quan L, Wright J, Fiser D, Zideman D, O'Malley P, and Chameides L. (1995). Recommended guidelines for uniform reporting of pediatric advanced life support: The pediatric Utstein Style. A statement for healthcare professionals from a task force of the American Academy of Pediatrics, the American Heart Association, and the European Resuscitation Council. Writing Group. Circulation 92:2006-2020.

Address correspondence to:

Monika Brodmann Maeder, MD, MME Institute of Mountain Emergency Medicine EURAC Research Viale Druso 1 Bolzano 39100 Italy

E-mail: monika.brodmann@eurac.edu

Received December 17, 2017; accepted in final form December 18, 2017. 